\title{
Perbandingan Bahan Bakar Premium Dengan Produk Cair Hasil Pyrolisis Plastik PET dan PP
}

\author{
Warandani Yulianto ${ }^{1)}$, Fatkur Rhohman ${ }^{2)}$, Nuryo Suwito ${ }^{3)}$. \\ ${ }^{1,2,3)}$ Teknik Mesin Universitas Nusantara PGRI Kediri \\ E-mail: ${ }^{1)}$ warandani@gmail.com, ${ }^{2}$ fr_kediri@yahoo.com, \\ ${ }^{3)}$ Suwito.unpkediri@gmail.com.
}

\begin{abstract}
Abstrak
Salah satu alternative penanganan sampah plastik yang saat ini banyak diteliti dan dikembangkan adalah mengubah sampah plastik menjadi bahan bakara alternatif. Tujuan penelitian ini adalah untuk memperoleh bahan bakar cair dari pirolisis sampah plastik, dengan nilai kalor dan mutu bahan bakar minyak yang baik. Metode yang digunakan adalah menggunakan proses pirolisis. Pirolisis atau devolatilisasi adalah proses fraksinasi material oleh suhu. Proses pirolisis dimulai pada temperature sekitar $500^{\circ} \mathrm{C}$, ketika komponen yang tidak stabil secara termal, dan volatile matters pada sampah akan pecah dan menguap bersamaan dengan komponen lainnya. Hasil dari proses pirolisis ini berupa cairan yang bisa digunakan sebagai bahan bakar alternatif, selain itu gas yang dihasilkan dari proses pirolisis juga dapat dimanfaatkan sebagai bahan bakar saat proses pirolisis berlangsung. Berdasarkan hasil eksperimen dan analisa data yang telah dilakukan, maka dapat diambil kesimpulan bahwa konsumsi bahan bakar plastik PET dan PP lebih rendah dari bahan bakar premium dengan perbedaan yang signifikan. Dimana bahan bakar plastik PET dan PP dengan nilai konsumsi bahan bakar rata-rata untuk kecepatan $2000 \mathrm{rpm}$ selama 2 menit sebesar $8,7 \mathrm{ml}$ sedangkan nilai konsumsi ratarata bahan bakar premium dengan kecepatan dan waktu yang sama sebesar $13 \mathrm{ml}$, sehingga dapat dipastikan hasil produk pirolisis plastik PET dan PP lebih irit daripada bahan bakar premium.

Kata Kunci: Pirolisis, Sampah plastik, Plastik PET, Plastik PP.
\end{abstract}

\begin{abstract}
One alternative to handling plastic waste that is currently being researched and developed is to change plastic waste into alternative fuels. The purpose of this study was to obtain liquid fuels from pyrolysis of plastic waste, with good heating value and quality of fuel oil. The method used is to use the pyrolysis process. Pyrolysis or devolatilization is the process of fractionating material by temperature. The pyrolysis process starts at a temperature of around $500{ }^{\circ} \mathrm{C}$, when components are thermally unstable, and volatile matters in the waste will break and evaporate along with other components. The result of this pyrolysis process is a liquid that can be used as an alternative fuel, besides the gas produced from the pyrolysis process can also be used as fuel during the pyrolysis process. Based on the results of experiments and data analysis that has been done, it can be concluded that the consumption of PET and PP plastic fuels is lower than premium fuels with significant differences. Where PET and PP plastic fuel with an average fuel consumption value of $2000 \mathrm{rpm}$ for 2 minutes is $8.7 \mathrm{ml}$ while the average consumption value of premium fuel with the same speed and time is $13 \mathrm{ml}$, so that results can be ascertained PET and PP plastic pyrolysis products are more economical than premium fuels.
\end{abstract}

Keywords: Pyrolysis, Plastic Waste, PET Plastic, PP Plastic. 


\section{PENDAHULUAN}

Sampah merupakan permasalahan komplek yang terjadi di masyarakat. Keberadaan sampah bila tidak dikelola dengan baik, bisa menjadi momok bagi keberlangsungan hidup umat manusia maupun alam. Pasalnya dalam segala aktifitasnya manusia hampir dipastikan menghasilkan yang namanya sampah. Sedangkan sampah itu sendiri bisa bermanfaat atau sebaliknya merugikan manusia, hal ini terutama sampah plastik.

Kemajuan teknologi membuat aktivitas produksi plastik terus meningkat. Hampir setiap produk menggunakan plastik sebagai kemasan atau bahan dasar. Material plastik banyak digunakan karena memiliki kelebihan dalam sifatnya yang ringan, transparan, tahan air serta harganya relatif murah dan terjangkau semua kalangan masyarakat. Segala keunggulan ini membuat plastik digemari dan banyak digunakan dalam setiap aspek kehidupan manusia, akibatnya jumlah produk plastik yang akan menjadi sampah pun terus bertambah. Setiap tahunnya limbah plastik menunjukkan peningkatan yang signifikan. Belum ada data pasti tentang prosentase jumlah sampah plastik yang dikelompokkan berdasarkan jenisnya. Berdasarkan data Kementerian Perindustrian tentang impor produk plastik dapat diprediksikan jumlah limbah yang akan timbul. Data dari Kementerian Perindustrian, impor produk polyethylene terephthalate (PET) dan polypropylene (PP) terus meningkat seiring dengan tumbuhnya konsumsi bahan kimia. Dalam data tersebut disebutkan, pada 2012 konsumsi PET di Indonesia sekitar 955.000 ton per tahun, yang meningkat menjadi sekitar 1,03 juta ton di tahun 2013, dan diprediksi di tahun 2014 meningkat menjadi 1,11 juta ton. Sama halnya dengan PET, konsumsi PP juga terus meningkat. Pada 2012, konsumsi PP sebesar 1,3 juta ton per tahun dan meningkat di tahun 2013 menjadi 1,46 juta ton. Pada 2014, konsumsi PP di prediksi meningkat menjadi 1,58 juta ton [1].

Data dari Kementerian Negara Lingkungan Hidup tahun 2007 menunjukkan, volume timbunan sampah di 194 kabupaten dan kota di Indonesia mencapai 666 juta liter atau setara 42 juta kilogram, di mana komposisi limbah plastik mencapai 14 persen atau 6 juta ton. Dari sumber yang sama di tahun 2012, jumlah sampah di 14 kota besar di Indonesia mencapai 1,9 juta ton. Adapun, jumlah limbah plastik secara umum pada tahun 2013 sebanyak 53\% dari jumlah sampah yang ada. Meningkatnya jumlah limbah plastik ini menjadi sebuah hal yang dapat 
mengancam kestabilan ekosistem lingkungan, mengingat plastik yang digunakan saat ini adalah non bio degradable (plastik yang tidak dapat terurai secara biologis). Plastik merupakan jenis sampah atau limbah yang proses penguraiannya membutuhkan waktu yang lama dan tidak ramah lingkungan [2].

Berbagai penelitian tentang pirolisis limbah plastik jenis PET (polyethylene terephthalate) dan PP (polypropylene) telah banyak dilakukan oleh beberapa peneliti sebelumnya. Pengolahan Sampah Plastik Jenis PP, PET dan PE Menjadi Bahan Bakar Minyak dan Karakteristiknya, plastik tipe PP menghasilkan minyak paling banyak dengan kebutuhan LPG paling sedikit dan waktu proses paling cepat [3]. Pada saat uji coba, plastik tipe PET tidak menghasilkan minyak tetapi menghasilkan material berbentuk serbuk. Minyak dari plastik tipe PP memiliki nilai kalor yang tinggi, lebih tinggi dari nilai kalor solar, bensin, LPG maupun minyak tanah. Minyak yang dihasilkan dari pengolahan plastik PP dan PE berdasarkan kandungan atom karbonnya mendekati bensin dan minyak tanah.

Wicaksono juga melakukan eksperimen alat pengolah sampah menjadi bahan bakar alternatif diperoleh hasil bahwa. Suhu pirolisis pada PET berlangsung efektif pada temperatur lebih dari $250^{\circ} \mathrm{C}$. Oil yang didapat pada pengujian parallel flow lebih banyak dibandingkan dengan counter flow. Volume oil pada proses pirolisis yang paling banyak yaitu pada suhu $260^{\circ} \mathrm{C}-350^{\circ} \mathrm{C}$ kondensor 1 lebih banyak menghasilkan minyak dibandingkan kondensor 2. Minyak yang dihasilkan kondensor 2 lebih murni karena mengandung materi hidrokarbon yang lebih ringan [4].

Sedangkan Endang menunjukan hasil bahwa minyak pirolisis terbanyak dari sampah plastik PP diperoleh dari proses pirolisis suhu $400^{\circ} \mathrm{C}$. Nilai densitas minyak hasil pirolisis plastik jenis PP mendekati nilai densitas dari minyak tanah dan solar. Nilai viskositas minyak hasil pirolisis PP mendekati nilai viskositas bensin. Nilai kalor minyak pirolisis hasil pirolisis PP mendekati nilai kalor solar. Nilai kalor pirolisis sampah plastik jenis PP meningkat dengan peningkatan suhu dinding reaktor.

Karakteristik fisika rata-rata bahan bakar minyak yang dihasilkan pada proses pirolisis dengan bahan baku plastik PP ini adalah densitas 0,8021gr/ml. Fraksi bahan bakar minyak yang didapatkan pada penggunaan katalis 1,5\% Zeolit A dan 
suhu $350^{\circ} \mathrm{C}$ adalah gasoline 32,56\% dan campuran kerosin - diesel sebesar $29,07 \%$. Pada penggunaan katalis $1,5 \%$ Zeolit A dan suhu $400^{\circ} \mathrm{C}$ adalah gasoline $36,28 \%$ dan campuran kerosin - diesel sebesar 34,51\%. Pada penggunaan katalis $1,5 \%$ Zeolit A dan suhu $450^{\circ} \mathrm{C}$ adalah gasoline $43,97 \%$ dan campuran kerosindiesel sebesar $31,03 \%$ dantanpa katalis pada suhu $450^{\circ} \mathrm{C}$ adalah gasoline $39,80 \%$ dan campuran kerosin-diesel sebesar $32,56 \%$.

Pengujian pada hasil proses pirolisis plastik PET juga menunjukkan bahwa, hasil cair dari proses pirolisis terbanyak adalah pada suhu $350{ }^{\circ} \mathrm{C}$ yaitu $160 \mathrm{ml}$. sedangkan nilai viskositas terendah pada sugu $300{ }^{\circ} \mathrm{C}$ sebesar $0,29 \mathrm{dPa} . \mathrm{S}$, nilai densitas terendah juga pada suhu $300{ }^{\circ} \mathrm{C}$ yaitu $780 \mathrm{~kg} / \mathrm{m}^{3}$. Dan nilai flash point terendah pada suhu $300{ }^{\circ} \mathrm{C}$ sebesar $34{ }^{\circ} \mathrm{C}$ [7].

Berdasarkan uraian diatas, peneliti tertarik melakukan penelitian tentang pengolahan limbah plastik. Peneliti mengambil judulInvestigasi bahan bakar cair hasil produk pyrolisis jenis plastik pet dan pp dibanding bahan bakar premium. Dengan adanya pengolahan limbah plastik menjadi bahan bakar alternatif ini, diharapkan dapat meminimalisir dampak yang diakibatkan dari sampah-sampah plastik tersebut, sehingga dapat bermanfaat bagi kehidupan kita. Selain itu bahan bakar alternatif juga bersifat ramah lingkungan sehingga dapat mengurangi polusi udara.

\section{METODE PENELITIAN}

Pada penelitian ini menggunakan dua variabel, yaitu variabel tetap dan variabel bebas. Variabel bebas pada penelitian ini adalah bahan bakar premium dan bahan baku produk hasil proses pirolisis, yaitu plastik PET dan PP. Sedangkan variabel tetapnya adalah jumlah konsumsi bahan bakar. Sedangkan teknik penelitian yang digunakan adalah teknik eksperimental, yaitu membandingkan jumlah konsumsi bahan bakar dari produk hasil pirolisis dengan premium.

Pada penelitian ini alat yang digunakan untuk proses pirolisis adalah sebagai berikut:

Perbandingan Bahan Bakar Premium Dengan Produk Cair Hasil Pyrolisis Plastik PET dan PP(Warandani Yulianto, Fatkur Rhohman, Nuryo Suwito) 


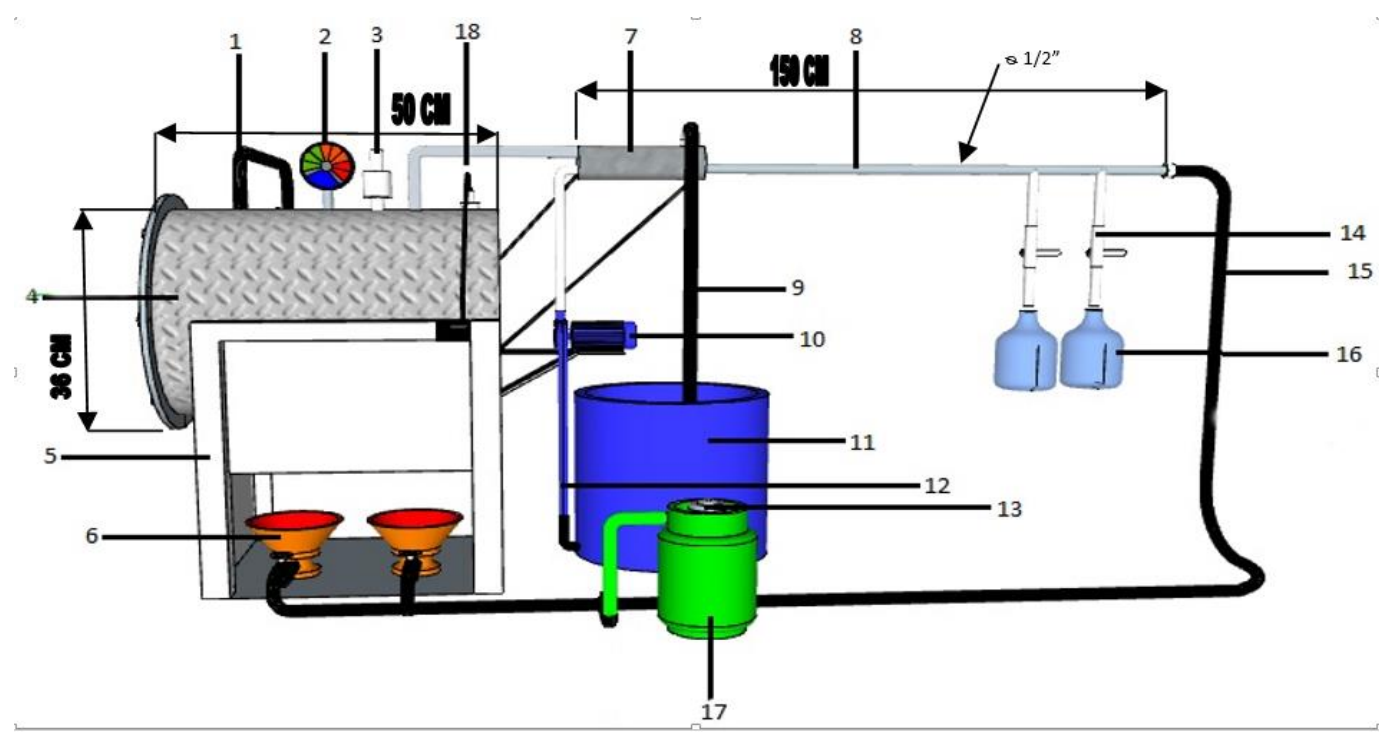

Gambar 1. Instalasi Peralatan Pengujian Pirolisis

Keterangan gambar:

1. Pipa saluran nitrogen

2. Manometer

3. Otomatisasi tekanan tinggi

4. Tabung reaktor

5. Rangka mesin

6. Kompor

7. Kondensor

8. Pipa alir

9. Pipa air kondensor
10.Pompa

11.Penampung air kondensor

12.Pipa masukan air kondensor

13. Regulator

14. Valve

15.Selang LPG

16. Wadah penampung cairan hasil pirolisis

17.Gas LPG

18. Termokopel

\section{HASIL DAN PEMBAHASAN}

Data hasil pengujian bahan bakar $200 \mathrm{ml}$ dengan waktu 2 menit dan kecepatan 2000 rpm untuk bahan bakar hasil pirolisis jenis plastik PET dan PP dan juga Premium.

Tabel 1 : Data Hasil Pengujian Nilai Konsumsi Bahan bakar

\begin{tabular}{|c|c|c|c|c|c|c|}
\hline \multirow{3}{*}{ No } & Jenis & \multirow{3}{*}{ Nilai Oktan } & \multirow{3}{*}{$\begin{array}{l}\text { Repli } \\
\text { kasi }\end{array}$} & \multirow{3}{*}{$\mathrm{X}_{1}$} & \multirow{3}{*}{$X_{2}$} & Konsumsi \\
\hline & Bahan & & & & & Bahan \\
\hline & Bakar & & & & & Bakar \\
\hline \multirow{3}{*}{1} & \multirow{3}{*}{$\begin{array}{c}\text { PET dan } \\
\text { PP }\end{array}$} & \multirow{3}{*}{95,6} & 1 & $200 \mathrm{ml}$ & $192 \mathrm{ml}$ & $8 \mathrm{ml}$ \\
\hline & & & 2 & $192 \mathrm{ml}$ & $183 \mathrm{ml}$ & $9 \mathrm{ml}$ \\
\hline & & & 3 & $183 \mathrm{ml}$ & $174 \mathrm{ml}$ & $9 \mathrm{ml}$ \\
\hline
\end{tabular}




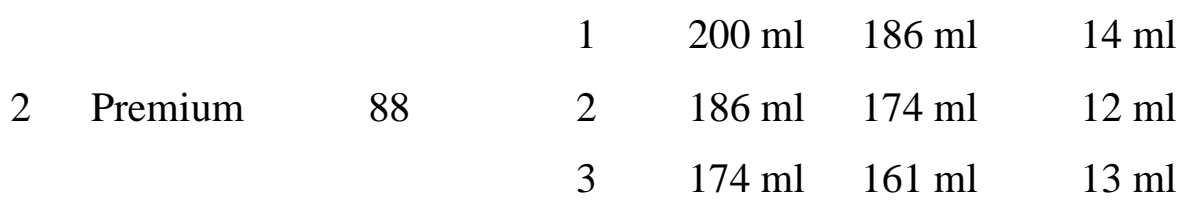

Dari tabel 1 data hasil pengujian berdasarkan percobaan sebanyak 3 kali, maka di peroleh hasil seperti di atas dan terlihat juga bahwa bahan bakar plastik PET dan PP lebih hemat dibandingkan bahan bakar Premium.

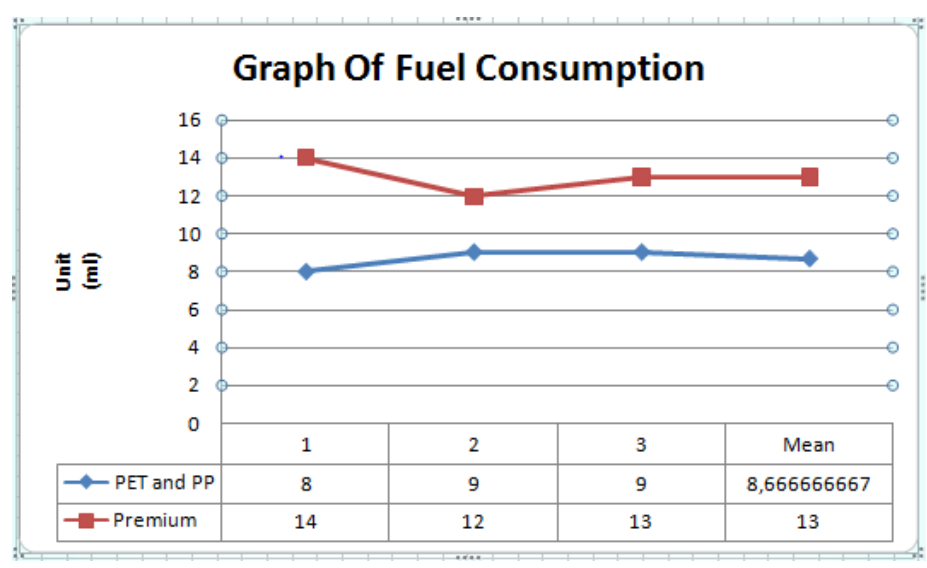

Gambar 2 : Grafik Nilai Konsumsi Bahan Bakar

\section{a. Density}

Dari hasil pengujian density menggunakan alat picnometer diperoleh hasil sebagai berikut:

Tabel 2 Nilai Density Dari Plastik PET dan PP

\begin{tabular}{ccccc}
\hline No & Jenis Bahan Bakar & Replikasi & Density $\left(\mathrm{gr} / \mathrm{cm}^{3}\right)$ & Rata-rata \\
\hline \multirow{2}{*}{1} & PET dan PP & 2 & 0.756415 & \\
& & 3 & 0.756021 & 0.756152 \\
& & 0.756021 & \\
\hline
\end{tabular}

Dari tabel diatas menunjukkan nilai density dari plastik PET dan PP memiliki nilai rata-rata sebesar $0.756152 \mathrm{gr} / \mathrm{cm}^{3}$.

\section{b. Viscosity}

Dari hasil pengujian viscosity menggunakan alat viscometer ostwald diperoleh hasil sebagai berikut:

Tabel 3 Nilai Viscosity Dari Plastik PET dan PP

\begin{tabular}{ccccc}
\hline No & Jenis Bahan Bakar & Replikasi & Viscosity $\left(\mathrm{mm}^{2} / \mathrm{s}\right)$ & Rata-rata \\
\hline 2 & PET dan PP & 1 & 1.858626 & 1.806774
\end{tabular}


Dari tabel di atas menunjukkan nilai viscosity dari plastik PET dan PP memiliki nilai rata-rata sebesar $1.806774 \mathrm{~mm}^{2} / \mathrm{s}$.

\section{c. Flash point}

Dari hasil pengujian flash point menggunakan alat Closed Cup diperoleh hasil sebagai berikut:

Tabel 4 Nilai Flash Point Dari PlastikPET dan PP

\begin{tabular}{ccccc}
\hline No & Jenis Bahan Bakar & Replikasi & Flash Point $\left({ }^{\circ} \mathrm{C}\right)$ & Rata-rata \\
\hline \multirow{2}{*}{3} & PET Murni & 2 & 6.5 & \\
& & 3 & 6 & 6.5
\end{tabular}

Dari tabel di atas menunjukkan nilai flash point dari bahan PET dan PP memiliki nilai rata-rata sebesar $6.5^{\circ} \mathrm{C}$.

Dari hasil tabel Density, Vicosity dan Flash Point,pada minyak hasil pirolisis jenis plastik PET dan PP di atas dapat digambarkan grafik sebagai berikut :

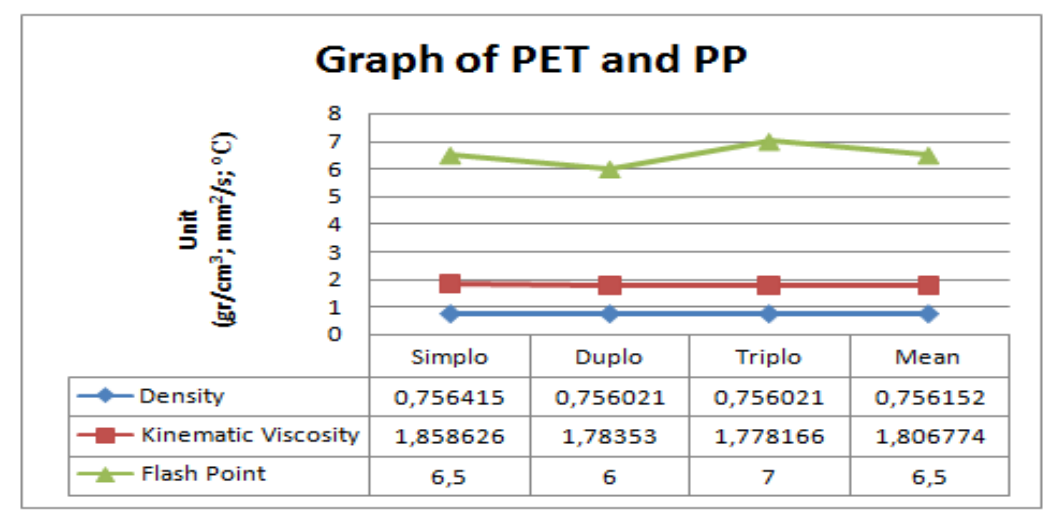

Gambar 3 Grafik Garis Plastik PET Dan PP

Dilihat pada tabel 2 bahwa konsumsi bahan bakar plastik PET dan PP lebih rendah dari bahan bakar premium dengan perbedaan yang signifikan. Dimana perbandinagan konsumsi bahan bakar plastik PET dan PP lebih kecil daripada Premium, sehingga dapat dipastikan hasil produk pirolisis plastik PET dan PP lebih irit daripada bahan bakar premium. Karena bahan bakar plastik PET dan PP memiliki nilai oktan 95,6 yang lebih tinggi dari bahan bakar premium yang hanya memiliki nilai oktan 88 . 


\section{KESIMPULAN}

Berdasarkan hasil eksperimen dan analisa data yang telah dilakukan, maka penelitian yang berjudul Investigasi Bahan Bakar Cair Hasil Produk Pyrolisis Jenis Plastik PET Dan PP Dibanding Bahan Bakar Premium. Dapat diambil kesimpulan bahwa konsumsi bahan bakar plastik PET dan PP lebih rendah dari bahan bakar premium dengan perbedaan yang signifikan. Dimana bahan bakar plastik PET dan PP dengan nilai konsumsi bahan bakar rata-rata untuk kecepatan 2000 rpm selama 2 menit sebesar 8,7 ml sedangkan nilai konsumsi rata-rata bahan bakar premium dengan kecepatan dan waktu yang sama sebesar $13 \mathrm{ml}$, sehingga dapat dipastikan hasil produk pirolisis plastik PET dan PP lebih irit daripada bahan bakar premium.

\section{DAFTAR PUSTAKA}

[1] K. Mustofa and F. Zainuri, "Pirolisis sampah plastik hingga suhu $900{ }^{\circ} \mathrm{C}$ sebagai upaya menghasilkan bahan bakar ramah lingkungan", Simposium Nasional RAPI XIII FT UMS, ISSN 1412-9612, 2014.

[2] Syamsiro M., Kajian Pengaruh Penggunaan Katalis Terhadap Kualitas Produk Minyak Hasil Pirolisis Sampah Plastik, Jurnal Teknik, vol. 5, no. 1, ISSN $2088-3676,2015$.

[3] Surono U.B. dan Ismanto, Pengolahan Sampah Plastik Jenis PP, PET dan PE Menjadi Bahan Bakar Minyak dan Karakteristiknya, Jurnal Mekanika dan Sistem Termal, vol. 1(1), April 2016 - ISSN : 2527-3841 ; e-ISSN : 25274910, 2016.

[4] Wicaksono M.A., Pengolahan Sampah Plastik Jenis PET (Polyethilene Perepthalathe) Menggunakan Metode Pirolisis Menjadi Bahan Bakar Alternatif, Jurnal Teknik Mesin Undip, Vol. 5, No. 1, 2017.

[5] Endang K., Mukhtar G., Abed N., F.X., Sugiyana A., "Pengolahan Sampah Plastik dengan Metoda Pirolisis menjadi Bahan Bakar Minyak", Seminar Nasional Teknik Kimia “Kejuangan”, ISSN 1693-4393, 2016.

[6] Priyatna A.O., Zultiniar, Saputra E., Perengkahan Katalitik Limbah Plastik Jenis Polypropylene (Pp) Menjadi Bahan Bakar Minyak Menggunakan Katalis Zeolit A, JOM FTEKTIK, Vol. 2, No. 2, 2015.

[7] Istiqlaliyah, H., "Characteristics Of Pet Plastic Pyrolysis Products With Temperature Variations", Prosiding Seminar Nasional Tahunan Teknik Mesin XVII Fakultas Teknik Universitas Nusa Cendana Kupang, 2018, pp. KE-13 178-82. 